\title{
Assay of the antioxidant capacity of foods using an iron(II)-catalysed lipid peroxidation model for greater nutritional relevance
}

\section{Short title: Assay of iron-binding antioxidant capacity}

Hélène L. Brangoulo ${ }^{1,2}$ and Peter C. Molan ${ }^{1}$

${ }^{1}$ Honey Research Unit, Department of Biological Sciences, University of Waikato, Hamilton, New Zealand

${ }^{2}$ Waikatolink, Innovation Park, Ruakura Road, Hamilton, New Zealand

*Corresponding author: Professor P. C. Molan, Department of Biological Sciences, University of Waikato, Private Bag 3105, Hamilton 3240, New Zealand

Tel: +647838.4325

Fax: +64 7838.4324

Email address: pmolan@waikato.ac.nz

Key words: Antioxidants; Fenton reaction; Lipid peroxidation; Iron sequestration; Free radicals 


\section{Abstract}

The formation of free radicals by the iron-catalysed Fenton reaction is a major cause of oxidative damage in the body. Here a common assay of antioxidant capacity, inhibition of the $\beta$-carotene-linoleic acid model of lipid peroxidation, has been modified by the addition of ferrous iron (final concentration $36 \mu \mathrm{mol} / 1$ ), which makes the rate of oxidation of the lipids occur twenty-five times faster. Such an assay can simulate the oxidative damage to membrane lipids and low density lipoproteins occurring in the body in the presence of free iron. It thus may be nutritionally more relevant than traditional chemical assays of antioxidant capacity, as it measures pre-emptive antioxidant activity, i.e. activity which prevents free radicals being formed in the first place. Pre-empting their formation is likely to be more protective than scavenging of free radicals. The relative antioxidant activity of some food products found using this new assay was very different from that found using a radical-scavenging assay. Vitamin C, at $280 \mathrm{mg} / \mathrm{l}$, was found to be sixty times better than blackcurrant puree in scavenging free radicals, but only one eighth as good as the blackcurrant puree in preventing iron-catalysed lipid peroxidation.

\section{Introduction}

Free radicals and reactive oxygen species (ROS) are involved in aging and major diseases such as neurodegenerative diseases, diabetes, atherosclerosis and cancer (Ames, Shigenaga \& Hagen, 1993; Halliwell, 1987; Van Campenhout, Van Campenhout, Lagrou, Moorkens, De Block \& Manuel-yKeenoy, 2006). Through its catalysis of the formation of free radicals from hydrogen peroxide (the Fenton reaction) iron in excess is believed to generate oxidative stress, and to induce and amplify lipid peroxidation reactions, leading to extensive oxidative damage to biomolecules (Lim, 2000; Puntarulo, 2005; Van Campenhout et al., 2006). Clinical conditions due to the oxidative effects of iron overload have been observed in cardiomyopathy, atherosclerosis, neoplasia and chronic disease such as liver disease, hematochromatosis, obesity and type II diabetes (Lim, 2000; Puntarulo, 2005; Van Campenhout et al., 2006). From a review of the widely dispersed literature it has been concluded that the role of 
poorly liganded iron has been rather underappreciated in the past, and that its activity is involved in the degradation of a great many physiological processes that is seen to occur over time (Kell, 2009). Thus supplementation of the diet with bioavailable antioxidants that not only scavenge free radicals but also have iron-sequestering activity that prevents the Fenton reaction from occurring would give the best protection to the body from oxidative damage. Hässig, Liang, Schwabl, \& Stampfli (1999) have pointed out that it has been shown that, depending on the iron status of the recipient, pharmacological doses of $\beta$-carotene and vitamins $\mathrm{C}$ and $\mathrm{E}$ sometimes have beneficial effects, but often also have no effect or harmful effects. They have argued that for a more reliable antioxidative action an adequate dietary supply of a mixture of flavonoids and tannins seems preferable, as these bind and inactivate iron.

Various in vitro assays such as the DDPH, ABTS or ORAC have been used to detect new potent free radical scavengers (Becker, Nissen \& Skibsted, 2004; Sanchez-Moreno, 2002). However these tests are just based on chemical reactions between scavengers and artificial free radicals and have no similarity with biological systems (Huang, Ou \& Prior, 2005). Nor do these tests measure the contribution made by the binding and inactivation of iron which prevents formation of free radicals, an antioxidant activity which biologically may be far more important than scavenging of free radicals. Directly measuring the ability of food products to sequester iron would not provide biologically useful information because chelation of iron does not always make it incapable of catalysing the Fenton reaction (Devanur, Neubert \& Hider, 2008).

Jayaprakasha, Singh \& Sakariah (2001) have developed an assay of antioxidant capacity using a $\beta$-carotene-linoleic acid model system which simulates the oxidative damage to cell membranes and low density lipoproteins caused by free radical chain reactions. The chemical reaction occurring in this system starts by the abstraction of a hydrogen atom from a diallylic methylene group of the linoleic acid. The resulting free radical oxidizes the double bonds of the $\beta$-carotene which is a chromophore characterized by an orange colour which can be measured. Antioxidant activity is determined as protection of the $\beta$-carotene from bleaching by oxidative damage. We have modified this assay to allow measurement of iron-sequestering antioxidant activity by addition of ferrous ions to catalyse the lipid 
peroxidation. Using this modified assay we have measured the inhibition of iron-catalysed lipid peroxidation by some food products reputed to have good antioxidant activity, and compared this with their antioxidant capacity assayed by the more usual measurement of free radical scavenging.

\section{Materials and Methods}

\subsection{Chemicals}

$\beta$-carotene, linoleic acid, Tween-40 (Polyoxyethylenesorbitan monopalmitate), Ferrozine ${ }^{\circledR}$ (3-(2Pyridyl)-5,6-diphenyl-1,2,4-triazine-4',4”-disulfonic acid sodium salt), Trolox ${ }^{\circledR}(( \pm)-6-H y d r o x y-2,5,7,8-$ tetramethylchromane-2-carboxylic acid), ABTS $^{\circledR}$ reagent $\quad$ (2,2'-azino-bis(3-ethylbenzthiazoline-6sulphonic acid), potassium persulphate and Vitamin C (ascorbic acid) were purchased from Sigma Aldrich (St Louis, MO, USA). Ferrous chloride was from BDH Chemicals Ltd (Poole, England). All reagents or solvents used were analytical grade.

\subsection{Food samples}

Honeydew (Nothofagus solandri) honey was from the West Coast, New Zealand. Thyme (Thymus vulgaris) honey was from the Central Otago region, New Zealand. Rewarewa (Knightia excelsa) honey was from the Bay of Plenty, New Zealand. The samples were collected as freshly produced honey and had been stored (for five years) at $4^{\circ} \mathrm{C}$ in the dark since collection. The red wine was a Breakneck Shiraz 2004 and was three years old when used. The blackcurrant puree (seedless) was manufactured by New Zealand Blackcurrant Co-operative Ltd, and had been stored (for one year) at $-20^{\circ} \mathrm{C}$ since production. The orange juice was freshly squeezed product from Simply Fresh Orange Juice Ltd, Kerikeri, New Zealand.

\subsection{Antioxidant activity using the $\beta$-carotene-linoleic acid model system}

The antioxidant activity of the samples was investigated using the $\beta$-carotene-linoleic acid model system of Jayaprakasha et al. (2001), with some modifications. In the method we used, a reaction 
mixture containing $100 \mathrm{mg}$ of Tween-40 and $10 \mathrm{mg}$ of linoleic acid was mixed with $1 \mathrm{ml}$ of $\beta$-carotene solution ( $4 \mathrm{mg} / \mathrm{ml}$ in chloroform). The chloroform was then removed, completely, at $40^{\circ} \mathrm{C}$ with a rotary evaporator and then $25 \mathrm{ml}$ of deionised purified purified water added, with thorough stirring, to form an emulsion. This emulsion was prepared just before use each time because the $\beta$-carotene loses its colour over a period of a few hours. For use as a reaction blank an emulsion was prepared in the same way but without any $\beta$-carotene in the chloroform.

A solution of $\mathrm{FeCl}_{2}$ at $0.25 \mathrm{mmol} / 1$ was freshly prepared in deionised purified water for catalysis of the system. A Ferrozine ${ }^{\circledR}$ standard solution at $1.5 \mathrm{mmol} / \mathrm{l}$ was prepared in deionised purified water, and a dilution series $(0.3-1.5 \mathrm{mmol} / \mathrm{l})$ from this was used to obtain a standard curve.

The food samples were diluted to an appropriate degree with deionised purified water so that the measured inhibition of decolourising of $\beta$-carotene was in the linear range of inhibition $(0-95 \%)$ seen in the Ferrozine ${ }^{\circledR}$ standard curve, and ideally was in the range of $50-80 \%$ inhibition of decolourising.

A 96-well flat-bottomed microtitre plate was loaded with $30 \mu \mathrm{l}$ of sample (solution of food product or Ferrozine ${ }^{\circledR}$ standard, or water as a control) and with $30 \mu 1$ of deionised purified water which was substituted by $30 \mu \mathrm{l}$ of $\mathrm{FeCl}_{2}$ solution $(250 \mu \mathrm{mol} / 1$, to give $36 \mu \mathrm{mol} / \mathrm{l}$ as final concentration $)$ when the catalytic effect of $\mathrm{Fe}^{2+}$ on the system was studied. The absorbance of the reaction mixture was measured at $450 \mathrm{~nm}$ after injecting $150 \mu \mathrm{l}$ of $\beta$-carotene emulsion into each well, using a Fluostar Optima microtitre plate reader (BMG Labtechnologies $\mathrm{GmbH}$, Offenburg, Germany) operated at $37^{\circ} \mathrm{C}$. The plate was shaken for 5 seconds immediately before injections were started, and for 2 seconds immediately before the measurements of absorbance which were at the beginning and end of the 10 minute or 180 minute period of reaction for each well. The first measurement $(\mathrm{t}=0 \mathrm{~min})$ for each well was made 4.5 seconds after injecting the emulsion.

The same sample was put in each of the eight wells in a row on the plate and the mean values of the absorbance readings from these eight replicates was taken for calculation of the antioxidant activity of the samples. A reaction blank was also prepared in a second row of each sample by adding $150 \mu 1$ of blank emulsion into each well instead of injecting the $\beta$-carotene emulsion. The absorbance due to the $\beta$ - 
carotene was calculated by subtracting the absorbance for each sample to which the blank emulsion had been added. The damage $(\%)$, measured as bleaching of the $\beta$-carotene, was calculated according to the equation:

$$
\text { Damage } \%=100 *\left[1-\left(\mathrm{A}_{\mathrm{t}} / \mathrm{A}_{\mathrm{o}}\right)\right]
$$

where $A_{t}$ and $A_{o}$ were respectively the absorbance due to $\beta$-carotene at a determined time $t$ (10 minutes for the catalysed system and 180 minutes for the non-catalysed system) and the starting absorbance at $\mathfrak{t}=0$ minutes.

The antioxidant activity (protective effect) of the samples was calculated according to the equation:

$$
\text { Protective effect } \%=[(\mathrm{DC}-\mathrm{DS}) / \mathrm{DC}] * 100
$$

where DC and DS were respectively the damage observed in the control and in the sample.

The protective effect (\%) obtained with the Ferrozine ${ }^{\circledR}$ standard was plotted against the Ferrozine ${ }^{\circledR}$ concentration. The linear regression from the standard curve gave the equation to convert the protective effect of the samples into the equivalent protective effect of Ferrozine ${ }^{\circledR}$ in mmol Ferrozine ${ }^{\circledR}$ per $\mathrm{kg}$ of food product.

\subsection{Free radical scavenging capacity using the ABTS assay}

The free radical scavenging capacity of the samples was determined according to the method of Baltrušaitytè, Venskutonis \& Ceksterytė (2007) with some modifications. This method measures the decrease in absorbance at $645 \mathrm{~nm}$ when the blue-coloured stable free radical ABTS ${ }^{\circ}$ is scavenged by antioxidants. In the method we used, the ABTS free radical was prepared by dissolving $38 \mathrm{mg}$ of ABTS reagent in $10 \mathrm{ml}$ of deionised purified water (final concentration was $7.0 \mathrm{mmol} / \mathrm{l}$ ). Then $6.5 \mathrm{mg}$ of potassium persulphate was added (final concentration was $2.45 \mathrm{mmol} / \mathrm{l}$ ) to the ABTS solution and allowed to react for 16 hours to form the stable $\mathrm{ABTS}^{\cdot+}$ radical cation. The $\mathrm{ABTS}^{\circ+}$ solution was further diluted with deionised purified water to get a final absorbance value between 2.0 and 2.4 at $645 \mathrm{~nm}$ 
when $100 \mu \mathrm{l}$ of this solution plus $100 \mu \mathrm{l}$ of water was mixed in a well of the microtitre plate and measured in the plate reader as described below.

A standard Trolox ${ }^{\circledR}$ solution was prepared at $0.2 \mathrm{mmol} / 1$ in absolute ethanol. The food samples were diluted to an appropriate degree with deionised purified water prior to analysis so that the measured decrease in absorbance values due to scavenging was in the linear response range of the decolourising of the radical solution (i.e. a decrease of $0-1.8$ ).

A 96-well flat-bottomed microtitre plate was loaded with $100 \mu 1$ of sample (solution of food product or Trolox ${ }^{\circledR}$ standard or water blank) and the absorbance was measured at $645 \mathrm{~nm}$ both before and 4.5 seconds after injecting into each well $100 \mu \mathrm{l}$ of $\mathrm{ABTS}^{{ }^{+}}$solution, using a Fluostar Optima microtitre plate reader (BMG Labtechnologies $\mathrm{GmbH}$, Offenburg, Germany) operated at $25^{\circ} \mathrm{C}$. The microtitre plate was shaken for 2 seconds after each injection before the absorbance was measured. The measurement in such a short period of time after mixing the ABTS $^{\cdot+}$ and the antioxidants avoided the error in the assay which can occur from the slow reaction between $\mathrm{ABTS}^{\circ+}$ and phenolic compounds (Osman, Wong, Hill \& Fernyhough, 2006).

The same sample was put in each of the eight wells in a row on the plate and the mean values of the absorbance readings from these eight replicates was taken for calculation of the antioxidant activity of the samples.

To allow for absorbance due to components of the food samples, the absorbance due to the $\mathrm{ABTS}^{++}$in each well was calculated by subtracting the absorbance measured before injection of the $\mathrm{ABTS}^{*+}$ solution from the absorbance measured after injection.

Using these corrected values for absorbance, the scavenging capacity of each sample was calculated according to the equation:

$$
\text { Scavenging capacity } \text { sample }=\mathrm{A}_{\text {control }}-\mathrm{A}_{\text {sample }}
$$


where $\mathrm{A}_{\text {control }}$ is the absorbance value of the $\mathrm{ABTS}^{-+}$solution after injecting it into wells with the water blank added instead of an antioxidant sample, and $\mathrm{A}_{\text {sample }}$ is the absorbance due to the residual (i.e. unscavenged) $\mathrm{ABTS}^{\circ+}$ after injecting it into the wells containing antioxidant sample.

The free radical scavenging antioxidant activity was expressed as Trolox ${ }^{\circledR}$-equivalent antioxidant capacity (TEAC), in mmol of Trolox ${ }^{\circledR}$ per $\mathrm{kg}$ of food product calculated according to the equation:

$$
\begin{aligned}
\text { TEAC }= & \left(\text { scavenging of sample } / \text { scavenging of Trolox }{ }^{\circledR}\right) * \text { Trolox }^{\circledR} \text { final concentration } \\
& *(1 / \text { Dilution factor of the sample })
\end{aligned}
$$

\section{Results and discussion}

In the control (no antioxidants added) the rate of reaction (observed as $\%$ damage to the $\beta$ carotene per minute) was twenty-five times greater with the ferrous ions added to catalyse the oxidative breakdown of lipid peroxides than without the addition of iron. The concentration of ferrous ions used had to have a substantial catalytic effect on the system but be low enough to give rates of bleaching of the $\beta$-carotene that were slow enough to be accurately measured. The concentration chosen, $36 \mu \mathrm{mol} / 1$, gave $70-80 \%$ bleaching in ten minutes. The period of 180 minutes used for the measurement of bleaching without iron added was a compromise between taking an excessively long period for the measurement and getting sufficient bleaching $(55-60 \%)$ to measure reliably.

Ferrozine $^{\circledR}$, a molecule known for efficiently sequestering ferrous iron, gave a linear relationship between inhibition $v s$ concentration in the iron-catalysed system. That made it a good standard against which to rate the iron-sequestering antioxidant activity of food samples in this model system.

Table 1 presents the data obtained on the antioxidant activity of food samples (expressed as Ferrozine $^{\circledR}$ equivalent) measured as inhibition of the bleaching of $\beta$-carotene catalysed by ferrous ions. The orange juice and thyme honey samples gave no protection at all from oxidative damage resulting from the Fenton reaction. However, the results from the assay of scavenging activity (also shown in Table 1) showed that these substances were efficient as free radical scavengers, the thyme honey being 
more than three times more active than the other honeys. These results proved that these commonly acknowledged antioxidants were not protecting against the damaging Fenton reaction. Big differences are seen in the other food products as well when their relative antioxidant activities are compared for the two types of assay. The red wine was found to be more than three times better than the Honeydew honey in scavenging free radicals, but only half as good as the Honeydew honey in protecting against damage from the Fenton reaction. Likewise, vitamin C, at a concentration of $280 \mathrm{mg} / \mathrm{l}$, was sixty times more effective than the blackcurrant puree in scavenging activity but had only one eighth of the capacity of the blackcurrant puree in protecting against damage from the Fenton reaction.

Bast, Haeneh \& Doelman (1991) reported that ferrous iron ions cause mild oxidation of polyunsaturated fatty acids, but the combination of vitamin $\mathrm{C}$ with either ferric or ferrous iron ions causes intense oxidation of polyunsaturated fatty acids: vitamin $\mathrm{C}$ up to a concentration of $35 \mathrm{mg} / \mathrm{l}$ potentiated peroxidation of lipids by $10 \mu \mathrm{mol} / \mathrm{l}$ ferrous iron, although vitamin $\mathrm{C}$ levels above this showed an antioxidant effect. Addition of a reducing agent, such as vitamin $\mathrm{C}$, to the Fenton reaction leads to a cycle which increases the damage to biological molecules, though recycling the ferric ions back to ferrous ions which are what drive the Fenton reaction (McNaught \& Wilkinson, 2003):

(i) $\mathrm{Fe}^{2+}+\mathrm{H}_{2} \mathrm{O}_{2} \rightarrow \mathrm{Fe}^{3+}+\mathrm{OH}^{\cdot}+\mathrm{OH}^{-}$

(ii) $\mathrm{Fe}^{3+}+$ reducing agent $\rightarrow \mathrm{Fe}^{2+}$

Vitamin C, however, can be advantageous nutritionally in preventing iron deficiency. Iron is essential as a constituent of haemoglobin and proteins involved in energy-yielding metabolism in the body. In his review of the literature on recommended dietary intake of iron, Herbert (1987) discusses the implications of the presence of iron-binding substances and vitamin $\mathrm{C}$ with respect to obtaining an adequate nutritional intake of iron. He points out that regular daily consumption of iron-binding substances such as tannins and flavonoids should be avoided when the iron status of an individual is compromised, as in cases of anaemia and in pregnancy, because these substances can decrease substantially the absorption of iron. He refers to vitamin $\mathrm{C}$ in the diet increasing the proportion of non- 
haem iron absorbed from food not containing animal material; however, he cites a finding that enhancing the absorbability of non-haem dietary iron with as much as $2 \mathrm{~g}$ of vitamin $\mathrm{C}$ daily for 2 years had little effect on iron status when the diet contained substantial amounts of meat.

Herbert (1987) also discusses the issue of iron toxicity, and quotes the tolerable upper intake levels of iron as being $40-45 \mathrm{mg}$ per day. Although stating that deleterious effects of daily intakes of several times the recommended daily allowance are unknown in healthy persons, he points out that of ostensibly normal individuals, $3-8$ of each 1000 may be homozygous for haemochromatosis and at definite risk of iron overload even at normal levels of intake of dietary iron.

With the concentrations of hydroperoxidases low in plasma under normal conditions (Halliwell \& Gutteridge, 1985; Halliwell \& Gutteridge, 1986), the release of metal ions which participate in the formation of harmful free radicals from hydrogen peroxide becomes particularly important (Cross et al., 1987). Although free iron that is available to participate in these reactions is apparently no higher than the $\mu \mathrm{mol} / \mathrm{l}$ range (Halliwell et al., 1986), the concentration of free iron is increased at sites of injury (Sadrzadeh, Anderson, Panter, Hallaway \& Eaton, 1987). This is at least partly because of the mobilisation of iron from ferritin in the presence of superoxide (produced by phagocytes) or vitamin C, as these reduce $\mathrm{Fe}^{3+}$ to $\mathrm{Fe}^{2+}$ which is not bound by the protein: as well as this, cellular destruction causes the release of cellular iron "transit pools" and also lysosomal hydrolases which in turn degrade metalloproteins (Cross et al., 1987; Halliwell et al., 1986). Additionally, the superoxide leaking from mitochondrial respiration causes release of iron from iron-sulphur proteins (Keyer \& Imlay, 1996). Iron is also released in erythrocytes subjected to oxidative stress, where it leads to haemolysis (Bracci, Perrone \& Buonocore, 2002). Another instance in which the concentration of free iron is increased is in alcoholics (De Feo et al., 2001). It has therefore been argued that the major antioxidant defense in extracellular fluids is the sequestration of metal ions into forms unable to participate in reactions forming free radicals (Halliwell \& Gutteridge, 1990; Halliwell et al., 1986; Halliwell \& Gutteridge, 1989). 
Relative to the sample of red wine, the Honeydew honey, Rewarewa honey and blackcurrant puree samples gave proportionally much better antioxidant activity measured as protection from oxidative damage in the iron-catalysed system compared with their activity in the radical scavenging system. The substances responsible for the antioxidant properties in these food samples may be the flavonoids. Flavonoids are known to be powerful antioxidants through free radical scavenging and transition metal chelating activities. These molecules are said to be poorly absorbed through the gut. However a study on mice fed with an excess of iron showed that the flavonoids quercetin and baicalin were reducing the oxidative damage to the iron-overloaded mouse livers and even helped clear the iron excess from the organism (Gao, Zhao, Li \& Zhang, 2006).

There are several mechanisms for non-enzymatic antioxidants to protect biomolecules. They can scavenge free radicals, sequester transition metal ions, inhibit oxidative enzymes or be a cofactor for antioxidant enzymes (Huang et al., 2005). A recent study on honey has proved that this food product may combine transition metal ion chelation and free radical scavenging activities (Hegazi \& AbdelHady, 2009). A study carried out by Al-Waili (2003) on the effects of daily consumption of honey on blood levels in normal individuals showed that honey was increasing the serum iron level but decreasing the content of ferritin, an iron storage protein. Those results indicate that the iron-sequestering substances in honey are bioavailable.

It has been found by van Acker et al. (1996) that different types of flavonoids vary markedly in their ability to sequester iron and render it inactive as a catalyst of the Fenton reaction. They report that some flavonoids are actually pro-oxidant in their action in the presence of iron because they can reduce $\mathrm{Fe}^{3+}$ to $\mathrm{Fe}^{2+}$ (which will then take part in the Fenton reaction). They also report that the ability to sequester iron is not related to the ability to suppress catalysis of the Fenton reaction, and that in some flavonoids the scavenging of free radicals is more important than the suppression of catalysis of the Fenton reaction, and vice versa. Furthermore they report that the lipophilicity of flavonoids is a very important factor in their inhibition of lipid peroxidation. The assay we report here, which allows for scavenging, lipophilicity and inhibition of catalysis, is thus far more likely than the commonly used 
assays of antioxidant activity to indicate the potential of flavonoid-containing foods to give protection in the body.

Another consideration is that very reactive free radicals have very short half-lives, so scavenging antioxidants give limited protection. The half-life of the hydroxyl radical is $10^{-9}$ seconds, so its reactions are diffusion limited, i.e. they take place practically at the site of generation (Sies, 1993). At the concentration of scavenging antioxidant molecules likely to be present in the tissues of the body, the probability of a scavenging antioxidant rather than a component of the body's tissues being at the site of generation of a hydroxyl radical is low, so damage to tissues will probably occur. However, an ironbinding antioxidant, if it can efficiently sequester iron in a non-catalytic form, is likely to be more effective by pre-empting the formation of the damaging hydroxyl radicals. This is another reason why the inhibition of iron-catalysed lipid peroxidation used in the present study is likely to be of more relevance to health protection when assessing antioxidant foods than are the more commonly used assays which measure scavenging of free radicals.

\section{Acknowledgments}

We thank members of the Honey Research Unit, Kerry Allen and Sam Lin, for their technical assistance and advice. We also thank Cathy Buntting, whose discovery in her MSc thesis study that honey inhibited the Fenton reaction led to our undertaking the present study.

This research was funded by Waiktolink Ltd., a company formed by the University of Waikato for commercialisation of the university's intellectual property. (Commercial use of the iron-binding antioxidant assay described in this paper may be restricted by a patent that is pending.)

\section{References}

Al-Waili, N. S. (2003). Effects of daily consumption of honey solution on hematological indices and blood levels of minerals and enzymes in normal individuals. Journal of Medicinal Food, 6(2), $135-140$. 
Ames, B. N., Shigenaga, M. K., \& Hagen, T. M. (1993). Oxidants, antioxidants, and the degenerative diseases of aging. Proceedings of the National Academy of Sciences of the United States of America, 90, 7915-7922.

Baltrušaitytė, V., Venskutonis, P. R., \& Ceksterytė, V. (2007). Radical scavenging activity of different floral origin honey and beebread phenolic extracts. Food Chemistry, 101(2), 502-514.

Bast, A., Haeneh, G. R. M. M., \& Doelman, C. J. A. (1991). Oxidants and antioxidants: state of the art. American Journal of Medicine, 91(suppl C), 2S-13S.

Becker, E. M., Nissen, L. R., \& Skibsted, L. H. (2004). Antioxidant evaluation protocols: food quality or health effects. European Food Research and Technology, 219, 561-571.

Bracci, R., Perrone, S., \& Buonocore, G. (2002). Oxidant injury in neonatal erythrocytes during the perinatal period. Acta paediatrica (Oslo, Norway : 1992). Supplement, 91(438), 130-134.

Cross, C. E., Halliwell, B., Borish, E. T., Pryor, W. A., Ames, B. N., Saul, R. L., McCord, J. M., \& Harman, D. (1987). Oxygen radicals and human disease. Annals of Internal Medicine, 107, 526545.

De Feo, T. M., Fargion, S., Duca, L., Cesana, B. M., Boncinelli, L., Lozza, P., Cappellini, M. D., \& Fiorelli, G. (2001). Non-transferrin-bound iron in alcohol abusers. Alcoholism: Clinical and Experimental Research, 25(10), 1494-1499.

Devanur, L. D., Neubert, H., \& Hider, R. C. (2008). The Fenton activity of iron(III) in the presence of deferiprone. Journal of Pharmaceutical Sciences, 97(4), 1454-1467.

Gao, Z., Zhao, Y., Li, H., \& Zhang, S. (2006). Dietary supplementation of baicalin and quercetin attenuates iron overload induced mouse liver injury. European Journal of Pharmacology, 535, 263-269.

Halliwell, B. (1987). Oxygen radicals and human disease - Davis conference. Annals of Internal Medicine, 107, 526-545.

Halliwell, B., \& Gutteridge, J. M. (1985). The importance of free radicals and catalytic metal ions in human diseases. Molecular Aspects of Medicine, 8(2), 89-193. 
Halliwell, B., \& Gutteridge, J. M. (1990). The antioxidants of human extracellular fluids. Archives of Biochemistry and Biophysics, 200(1), 1-8.

Halliwell, B., \& Gutteridge, J. M. C. (1986). Oxygen free radicals and iron in relation to biology and medicine: some problems and concepts. Archives of Biochemistry and Biophysics, 246(2), 501514.

Halliwell, B., \& Gutteridge, J. M. C. (1989). Free radicals in biology and medicine. Oxford: Clarendon Press.

Hässig, A., Liang, W. X., Schwabl, H., \& Stampfli, K. (1999). Flavonoids and tannins: plant-based antioxidants with vitamin character. Medical Hypotheses, 52(5), 479-481.

Hegazi, A. G., \& Abdel-Hady, F. K. (2009). Influence of honey on the suppression of human low density lipoprotein (LDL) peroxidation (in vitro). Evidence-Based Complementary and Alternative Medicine : eCAM, 6(1), 113-121.

Herbert, V. (1987). Recommended dietary intakes (RDI) of iron in humans. American Journal of Clinical Nutrition, 45, 679-686.

Huang, D., Ou, B., \& Prior, R. L. (2005). The chemistry behind antioxidant capacity assays. Journal of Agricultural and Food Chemistry, 53, 1841-1856.

Jayaprakasha, G. K., Singh, R. P., \& Sakariah, K. K. (2001). Antioxidant activity of grape seed (Vitis vinifera) extracts on peroxidation models in vitro. Food Chemistry, 73(3), 285-290.

Kell, D. B. (2009). Iron behaving badly: inappropriate Iron chelation as a major contributor to the aetiology of vascular and other progressive inflammatory and degenerative diseases. $B M C$ Medical Genomics, 2(1), 2.

Keyer, K., \& Imlay, J. A. (1996). Superoxide accelerates DNA damage by elevating free-iron levels. Proceedings of the National Academy of Sciences of the United States of America, 93(24), 1363513640.

Lim, P. (2000). Lipophilic antioxidants and iron status in ESRD patients on hemodialysis. Nephron, 86, $428-435$. 
McNaught, A. D., \& Wilkinson, A. (2003). IUPAC Compendium of Chemical Terminology, online version. http://old.iupac.org/goldbook/FT06786.pdf. Last viewed 29 April 2010.

Osman, A. M., Wong, K. K., Hill, S. J., \& Fernyhough, A. (2006). Isolation and the characterization of the degradation products of the mediator ABTS-derived radicals formed upon reaction with polyphenols. Biochemical and biophysical research communications, 340(2), 597-603.

Puntarulo, S. (2005). Iron, oxidative stress and human health. Molecular Aspects of Medicine, 26, 299312.

Sadrzadeh, S. M., Anderson, D. K., Panter, S. S., Hallaway, P. E., \& Eaton, J. W. (1987). Hemoglobin potentiates central nervous system damage. Journal of Clinical Investigation, 79(2), 662-664.

Sanchez-Moreno, C. (2002). Review: Methods used to evaluate the free radical scavenging activity in foods and biological systems. Food Science and Technology International, 8(3), 121-137.

Sies, H. (1993). Strategies of antioxidant defense. European Journal of Biochemistry, 215(2), 213-219.

van Acker, S. A., van den Berg, D. J., Tromp, M. N., Griffioen, D. H., van Bennekom, W. P., van der Vijgh, W. J., \& Bast, A. (1996). Structural aspects of antioxidant activity of flavonoids. Free Radical Biology and Medicine, 20(3), 331-342.

Van Campenhout, A., Van Campenhout, C., Lagrou, A. R., Moorkens, G., De Block, C., \& Manuel-yKeenoy, B. (2006). Iron-binding antioxidant capacity is impaired in diabetes mellitus. Free Radical Biology and Medicine, 40(10), 1749-1755. 
Table 1. Antioxidant capacity of food samples measured by inhibition of the Fenton reaction (expressed as the equivalent concentration of Ferrozine ${ }^{\circledR}$ with the same capacity) and by free-radical scavenging (expressed as the equivalent concentration of Trolox ${ }^{\circledR}$ with the same capacity). Values are expressed as means \pm standard deviation $(\mathrm{n}=3)$.

\begin{tabular}{|c|c|c|}
\hline Sample & $\begin{array}{c}\text { Ferrozine }^{(\mathbb{R}} \text { equivalent }^{\text {(in mmol/kg of sample) }} \\
\text { Honeydew honey }\end{array}$ & $\begin{array}{c}\text { Trolox }^{(B)} \text { equivalent } \\
\text { (in mmol/kg of sample) }\end{array}$ \\
\hline Rewarewa honey & $9.6 \pm 0.3$ & $3.2^{\text {a }} \pm 0.2^{\mathrm{a}}$ \\
\hline Thyme honey & $4.4 \pm 0.4^{\mathrm{a}}$ & $3.0 \pm 0.2^{\mathrm{a}}$ \\
\hline Red wine & 0 & $11.2 \pm 0.6^{\mathrm{b}}$ \\
\hline Blackcurrant & $4.8 \pm 0.2^{\mathrm{a}}$ & $10.1 \pm 0.7^{\mathrm{b}}$ \\
\hline Orange juice & $58.8 \pm 10.3$ & $45.0 \pm 5.9$ \\
\hline Vitamin C & 0 & $5.1 \pm 0.4$ \\
\hline
\end{tabular}

